\title{
A produção científica nacional sobre os direitos da criança hospitalizada
}

\section{The national scientific production about on the rights of the hospitalized child}

\section{La producción científica nacional sobre los derechos del niño hospitalizado}

\author{
Fernanda Martins de Aquino', Monique C. Monteiro Lemos"', Taisa Rodrigues da Silva'"I \\ Marialda Moreira Christoffel ${ }^{\mathrm{IV}}$
}

\section{RESUMO}

Este estudo objetivou identificar a produção científica nacional sobre os direitos da criança e do adolescente hospitalizados e analisar o papel do enfermeiro, enquanto profissional de saúde, na perspectiva desses direitos. Trata-se de uma revisão bibliográfica nas bases de dados LILACS e SCIELO, no período de 1996 a 2008, em que foram analisados 13 artigos na íntegra. Os resultados revelam que, apesar de os artigos abordarem os direitos da criança hospitalizada, apenas um deles fazia referência à Resolução no 41/95 que trata dos Direitos da Criança e do Adolescente. Conclui-se que é de suma importância que as enfermeiras pediátricas esclareçam e assegurem aos pais o direito de participação ativa na hospitalização de seu filho.

Palavras chaves: Direitos da criança; Hospitalização; Enfermagem Pediátrica.

\section{ABTRACT}

This study aim is to identify the national scientific production on the child's rights and hospitalized adolescent and to analyze the paper of the nurse, as a health professional, in the perspective of these rights. One is about a bibliographical revision in the databases LILACS and SciELO, in the period of 1996 the 2008, where 13 articles in it complete form were analyzed. The results disclose that, although the articles approach the rights of hospitalized child, but 01 article make reference to the Resolution no $41 / 95$ wich deals with the Rights of the Child and Adolescent. The conclusion it is relevant that pediatric nurses clarify the parents about the right of active participation in the hospitalization of their kids or adolescents.

Key words: Child Advocacy; Hospitalization; Pediatric Nursing

\section{RESUMEN}

El objetivo de este estudio es identificar la producción científica nacional sobre los derechos del niño y adolescente hospitalizados y analizar el papel de la enfermera, como profesional de la salud, en la perspectiva de estos derechos. Uno de ellos es acerca de una revisión bibliográfica en las bases de datos LILACS y SciELO, en el período de 1996 hasta 2008, cuando 13 artículos en forma completa fueron analizados. Los resultados revelaron que, si bien los artículos enfoque de los derechos de los niños hospitalizados, sólo el artículo 01 hace referencia a la Resolución n 41/95 que se ocupa de los Derechos del Niño y del Adolescente. Se concluye que es importante que las enfermeras pediátricas aclaren los padres sobre el derecho de participación activa en la hospitalización de sus hijos o adolescentes.

Palabras clave: Defensa del Niño; Hospitalización; Enfermería Pediátrica.

\footnotetext{
Aluna do 6o período do curso de graduação em enfermagem e obstetrícia EEAN/UFRJ. Email: fernandaeean@yahoo.com.br.

" Aluna do 60 período do curso de graduação em enfermagem e obstetrícia EEAN/UFRJ. Email: monique.lemos@bol.com.br.

III Aluna do 6o período do curso de graduação em enfermagem e obstetrícia EEAN/UFRJ. Email: ufrj.taisa@gmail.com.

IV Professora Adjunta Departamento de Enfermagem Materno-Infantil. EEAN/UFRJ. Pesquisadora NUPESC. Email: marialdanit@gmail.com.
} 


\section{NTRODUÇÃO}

A criança e o adolescente se constituem de um grupo vulnerável a doença e a hospitalização, pois elas afastam a criança de sua vida cotidiana, do ambiente familiar e promove um confronto com a dor, a limitação física e a passividade, aflorando sentimentos de culpa, punição e medo da morte. A doença e a hospitalização são as primeiras crises que a criança e o adolescente têm de enfrentar durante a vida ${ }^{(1)}$.

Muitas vezes, as reações da criança são influenciadas pelo seu estágio de desenvolvimento, por suas experiências anteriores com doenças ou hospitalização ou pela gravidade de diagnóstico.

A hospitalização para a criança e o adolescente traz um sentimento de ameaça, agressão, medo do desconhecido, pois é nesse momento que ocorre a separação de todos os objetos significativos de sua segurança, por outro lado à família retorna para casa cheia de angústia, ansiedade e sentimento de culpa.

A criança não pode ser compreendia de forma isolada, desconsiderando o todo como ser humano e o seu contexto histórico, na qual está inserida, além também, das necessidades de cuidados para o corpo, com alimentação e aprendizado. A ligação afetiva entre a criança e a família, e mais objetivamente com a mãe é imprescindível para assegurar que as bases de formação psicológica do futuro adulto sejam mantidas intactas ${ }^{(2)}$.

Informar a criança/adolescente e pais sobre os seus direitos durante a hospitalização garante uma maior compreensão da situação e pode aliviar parte dos sentimentos como medo e ansiedade que eles tipicamente sentem.

Um dos maiores marcos na atenção integral a infância é a aprovação da Lei no 8069, Estatuto da Criança e do Adolescente $\mathrm{ECA}^{(3-4)}$, que trata dos princípios da proteção social e da criança como sujeito de direitos. Em seu Livro I, Parte Geral, Título I: "das Disposições Preliminares trata dos Direitos fundamentais: vida, saúde, alimentação, educação, esporte lazer, cultura, dignidade, respeito, liberdade, convivência familiar e comunitária". O ECA define criança como a pessoa até doze anos de idade incompletos, e adolescentes aqueles entre doze e dezoito anos.
Assegura a efetivação dos direitos, levando em conta a condição peculiar da criança e do adolescente como pessoas em desenvolvimento.

O Título II dos Direitos Fundamentais, Capítulo I - Vida e Saúde referem a permanência dos pais ou responsáveis em tempo integral nos casos de internação da criança e do adolescente. A família, comunidade, sociedade em geral e o poder público são obrigados a assegurar estes direitos $^{(3,5-6)}$.

Durante o processo de hospitalização da criança e do adolescente, a presença dos pais, além de ser uma necessidade para minimizar os efeitos da separação, atualmente, é legislada pelo Estatuto da Criança e do Adolescente, no Capítulo I, Art. 12․ que garante a "...permanência em tempo integral de um dos pais ou responsável, nos casos de internação de criança ou adolescente" $1(3,7)$.

Os hospitais que prestam serviço a crianças e adolescentes devem ter uma ampla política de direitos e responsabilidades desses pacientes e /ou responsáveis. Um número cada vez maior de hospitais e organizações desenvolveu a Declaração de Direitos do paciente que é exposto por todo o hospital ou é apresentado ás crianças e às suas famílias no momento da admissão(1).

No Brasil, a Resolução no 41 de 1995 do Conselho Nacional dos Direitos da Criança e dos Adolescentes\CONANDA ${ }^{(8)}$, trata dos Direitos da Criança e do Adolescente Hospitalizados. Nesse documento estão descritos vinte itens, dentre eles: "o direito a ser hospitalizado quando for necessário ao seu tratamento, sem que haja distinção de classe social, condição econômica, raça ou crença religiosa; o direito de ter conhecimento adequado de sua enfermidade, dos cuidados terapêuticos e diagnósticos, respeitando sua fase cognitiva, além de receber amparo psicológico quando se fizer necessário; o direito de desfrutar de alguma forma de recreação, programas de educação para a saúde e acompanhamento do currículo escolar, direito a que seus pais ou responsáveis participem ativamente do diagnóstico, tratamento e prognóstico, recebendo informações sobre os procedimentos a que será submetida"(8).

Nos países da Europa, A Carta da Criança Hospitalizada foi encaminhada ao Parlamento de 
Estrasburgo, Conselho da Europa e Organização de Saúde, em $1988^{(9)}$. Estes documentos resumem e afirmam os direitos das crianças e adolescentes hospitalizados e até hoje tem sua importância(3,8-9)

O Código de Ética dos Profissionais de Enfermagem (10), em seu Art. 1으, "confirma o compromisso da enfermagem com 0 ser humano e a coletividade nos diferentes níveis de promoção, prevenção e recuperação". Logo, o enfermeiro atua durante a hospitalização das crianças e adolescentes, visando não só o cuidado com o seu problema de saúde atual, como também o seu desenvolvimento físico, mental, moral, espiritual e social, o que está garantido no Art. 3o do $\mathrm{ECA}^{(3-4)}$.

Portanto o cuidado de enfermagem não deve ser desvinculado da família e de suas necessidades, o que implica no domínio de informações teóricas específicas e ao desenvolvimento de uma sensibilidade especial para lidar com esta clientela ${ }^{(6)}$.

Desta forma, os objetivos deste estudo são: identificar a produção científica nacional sobre os direitos da criança e do adolescente hospitalizados; e analisar sobre o papel do enfermeiro, enquanto profissional de saúde, na perspectiva desses direitos.

O desenvolvimento desse estudo pressupõe que a Resolução no 41/95 do CONANDA $^{(8)}$ é pouco conhecida pelos profissionais de saúde, principalmente pela enfermagem pediátrica, pais e familiares.

Esperamos contribuir para a assistência visando à melhoria da atenção fornecida a criança e ao adolescente e seus familiares durante a hospitalização. Para o ensino, esperamos contribuir como fonte de consulta e ampliação de conhecimentos dos profissionais de saúde e de enfermagem na perspectiva da garantia dos direitos das crianças e adolescentes. Na pesquisa, como base científica a ser consultada além de fomentar outros estudos.

\section{METODOLOGI A}

Estudo de revisão de literatura, que é definida como uma revisão sistemática e crítica das literaturas especializadas mais importantes publicadas a respeito de um tópico específico ${ }^{(11)}$.
A revisão bibliográfica é composta por dez etapas que são: determinar o tema, identificar termos-chave, conduzir a busca no computador, descartar fontes irrelevantes antes de imprimir, organizar as fontes impressas, arquivar fontes relevantes, fazer cópia dos artigos, conduzir a leitura preliminar e descartar fontes irrelevantes, ler criticamente cada fonte e sintetizar e fazer uma leitura crítica resumida de cada artigo(11).

Logo, para efetivar a realização do estudo a respeito da produção científica nacional sobre os direitos da criança e do adolescente hospitalizado e a atuação da enfermeira pediátrica, optamos por uma pesquisa em base de dados pela internet. Através do site da Biblioteca Regional de Medicina (BIREME), realizamos um levantamento das produções científica indexada nas bases de dados: Literatura Latino-Americana e do Caribe (LILACS) e Scientific Electronic Libary On line (SCIELO).

Foram utilizados os seguintes descritores: "direitos da criança, hospitalização, enfermagem". Desta forma, foram encontradas as seguintes produções científicas: 140 na base de dados LILACS e 10 na base de dados SciELO, totalizando 150 produções científicas.

Os critérios de inclusão adotados neste estudo foram: selecionar as produções científicas em forma de artigo na íntegra e o recorte temporal 1996 a 2008.

Das 150 produções científicas encontradas, apenas 13 artigos tratavam da temática do estudo. Após leitura exaustiva dos artigos, utilizamos a técnica de análise temática que consiste em descobrir os núcleos de sentido que compõem uma comunicação cuja presença ou freqüência signifiquem alguma coisa para o objetivo analítico visado ${ }^{(12)}$.

Embora tenhamos clareza de que esta pesquisa não contempla todas as publicações brasileiras sobre a temática, acreditamos que a análise dos artigos possibilitará um conhecimento maior aos profissionais e acadêmicos da área da saúde, principalmente da enfermagem, norteando-os para as publicações mais atuais que abordam os direitos das crianças hospitalizadas e de que forma este tema vem sendo explorado. 


\section{RESULTADOS E DISCUSSÃO}

Constatamos que do total de 13 artigos, no recorte temporal de 1996 a 2008, foram encontradas: $02(15,4 \%)$ artigos publicados em 1996, $03(23,1 \%)$ artigos publicados no ano de
1998, $05(38,5 \%)$ artigos publicados no ano de 1999, 01 artigo publicados (7,7\%) em 2004 e 02 artigos publicados $(15,4 \%)$ em 2005, conforme mostra a Tabela 1.

Tabela 01: Relação dos artigos pesquisados segundo: ano de publicação, periódico, título do artigo, tipo de estudo e citação ECA|Resolução no. 41\95.

\begin{tabular}{|c|c|c|c|c|}
\hline $\begin{array}{c}\text { Ano de } \\
\text { publicação }\end{array}$ & Periódico & Título do artigo & Tipo do estudo & Citações \\
\hline 1996 & $\begin{array}{l}\text { Revista Latino } \\
\text { Americana de } \\
\text { Enfermagem }\end{array}$ & $\begin{array}{c}\text { Reflexões sobre o preparo do } \\
\text { enfermeiro na área de oncologia } \\
\text { pediátrica }\end{array}$ & Pesquisa reflexiva & - \\
\hline 1996 & $\begin{array}{l}\text { Revista Escola de } \\
\text { Enfermagem }\end{array}$ & $\begin{array}{l}\text { Preparo da criança e família para } \\
\text { procedimentos cirúrgicos: } \\
\text { intervenção de enfermagem }\end{array}$ & $\begin{array}{l}\text { Estudo } \\
\text { bibliográfico }\end{array}$ & - \\
\hline 1998 & $\begin{array}{l}\text { Revista Latino } \\
\text { Americana de } \\
\text { Enfermagem }\end{array}$ & $\begin{array}{c}\text { Um estudo bibliográfico sobre o } \\
\text { apego mãe e filho: bases para a } \\
\text { assistência de enfermagem } \\
\text { pediátrica e neonatal }\end{array}$ & $\begin{array}{l}\text { Revisão } \\
\text { bibliográfica }\end{array}$ & ECA \\
\hline 1998 & $\begin{array}{l}\text { Revista Latino } \\
\text { Americana de } \\
\text { Enfermagem }\end{array}$ & $\begin{array}{l}\text { Prescrição do dia: infusão de } \\
\text { alegria. Utilizando a arte como } \\
\text { instrumento na assistência à } \\
\text { criança hospitalizada }\end{array}$ & $\begin{array}{l}\text { Relato de } \\
\text { experiência }\end{array}$ & - \\
\hline 1998 & $\begin{array}{l}\text { Revisto Latino } \\
\text { Americana de } \\
\text { Enfermagem }\end{array}$ & $\begin{array}{l}\text { Fontes e significados de cuidar e } \\
\text { não cuidar em hospital pediátrico }\end{array}$ & Estudo exploratório & - \\
\hline 1999 & $\begin{array}{l}\text { Revista Latino- } \\
\text { Americana de } \\
\text { Enfermagem }\end{array}$ & $\begin{array}{l}\text { Assistência à criança hospitalizada: } \\
\text { reflexões acerca da participação dos } \\
\text { pais. }\end{array}$ & Qualitativo & ECA (Art 12) \\
\hline 1999 & $\begin{array}{l}\text { Revista Latino- } \\
\text { Americana de } \\
\text { Enfermagem }\end{array}$ & $\begin{array}{c}\text { Criança hospitalizada: percepção } \\
\text { das mães sobre o vínculo afetivo } \\
\text { criança-família }\end{array}$ & Qualitativo & ECA (Art 12) \\
\hline 1999 & $\begin{array}{l}\text { Revista Escola de } \\
\text { Enfermagem USP }\end{array}$ & $\begin{array}{c}\text { Brincar no Hospital: Subsídios Para } \\
\text { O Cuidado de Enfermagem }\end{array}$ & $\begin{array}{l}\text { Observação } \\
\text { participante }\end{array}$ & ECA (Art 16) \\
\hline 1999 & $\begin{array}{l}\text { Acta paulista de } \\
\text { enfermagem }\end{array}$ & $\begin{array}{l}\text { Interação enfermeira-mãe da } \\
\text { criança hospitalizada: estudo do } \\
\text { efeito do método de Roy. }\end{array}$ & $\begin{array}{c}\text { Pesquisa } \\
\text { experimental }\end{array}$ & ECA \\
\hline 1999 & $\begin{array}{l}\text { Revista Pediatria } \\
\text { Moderna }\end{array}$ & $\begin{array}{c}\text { Equipe de enfermagem, criança } \\
\text { com câncer e sua família: uma } \\
\text { relação possível. }\end{array}$ & Observação & - \\
\hline 2004 & $\begin{array}{l}\text { Revista Latino- } \\
\text { americana de } \\
\text { enfermagem }\end{array}$ & $\begin{array}{l}\text { Criança hospitalizada: mãe e } \\
\text { enfermagem compartilhando o } \\
\text { cuidado }\end{array}$ & Estudo de caso & ECA (Art. 12) \\
\hline 2005 & $\begin{array}{l}\text { Revista Latino- } \\
\text { americana de } \\
\text { enfermagem }\end{array}$ & $\begin{array}{l}\text { As informações recebidas pelos pais } \\
\text { durante a hospitalização do filho }\end{array}$ & Quantitativa & $\begin{array}{l}\text { ECA (Art. } \\
12) ; \\
\text { Resolução } \\
41 / 95 \\
\end{array}$ \\
\hline 2005 & $\begin{array}{l}\text { Revista Latino- } \\
\text { americana de } \\
\text { enfermagem }\end{array}$ & $\begin{array}{c}\text { Procurando manter o equilíbrio para } \\
\text { atender suas demandas e cuidar da } \\
\text { criança hospitalizada: a experiência } \\
\text { da família. }\end{array}$ & Qualitativa & - \\
\hline
\end{tabular}

Em relação a origem da publicação e ao periódico, $08(61,5 \%)$ foram realizados na região Sudeste e $05(38,5 \%)$ na região Sul do Brasil. Destes $09(69,2 \%)$ foram publicados na Revista Latino-Americana de Enfermagem, 02 $(15,4 \%)$ na Revista Escola de Enfermagem/
USP, 01 (7,7\%), na Acta Paulista de Enfermagem e 01 (7,7\%) na Revista de Pediatria Moderna.

No que se refere aos profissionais que desenvolveram os estudos sobre a temática, 12 $(92,3 \%)$ foram realizados por enfermeiros, 
docentes e acadêmicos de enfermagem e apenas $01(7,7 \%)$ por enfermeiro e psicólogos.

Em relação à metodologia adotada, 06 $(46,2 \%)$ são estudos qualitativos, $04(30,8 \%)$ estudos quantitativos, $02(15,4 \%)$ revisões de literatura, $01(7,7 \%)$ pesquisa reflexiva.

Foi observado que somente 07 (53,9\%) artigos citam em seu desenvolvimento o Estatuto da Criança e do Adolescente. Dos 13 artigos analisados, $04(30,8 \%)$ citam o Art. 12응 do ECA, sendo que um deles aborda a Resolução no. $41 \backslash 95$ do CONANDA ${ }^{(8)}$. Pudemos observar que $02(15,4 \%)$ não tratam especificamente de nenhum artigo dispostos no $\operatorname{ECA}^{(3)}$ e apenas $01(7,7 \%)$ aborda o Art. 16o.

Da análise do conteúdo dos artigos selecionaram emergiram três categorias: 1) o direito da criança de ser acompanhada durante a hospitalização, 2) o direito de desfrutar de alguma forma de recreação e 3) os direitos a ter seus direitos constitucionais e os contidos no estatuto da criança e adolescente, respeitados pelos hospitais integralmente.

\section{O direito da criança de ser acompanhada durante a hospitalização}

O Estatuto da Criança e do Adolescente em seu Capítulo I, Art. 12을 garante a permanência em tempo integral de um dos pais ou responsável, nos casos de internação de uma criança ou adolescente. Além disso, está assegurado aos pais receberem informações claras, objetivas e compreensíveis sobre a hipótese diagnóstica, exames solicitados, ações terapêuticas $^{(3)}$. O Art. 4ㅇ da Resolução no 41/95, do CONANDA, reforça ainda, o direito a criança de ser acompanhado por sua mãe, pai ou responsável, durante todo o período de sua hospitalização, bem como receber visitas ${ }^{(8)}$.

No que diz respeito aos pais ou responsáveis da criança hospitalizada podemos evidenciar que os $\operatorname{artigos}^{(4,13)}$ abordam esta temática com o objetivo de conhecer a percepção dos pais quanto ao tipo de informações recebidas das enfermeiras durante a permanência do filho no hospital, compreender o significado das interações vivenciadas pela família durante a hospitalização e analisar a participação dos pais neste processo.
A hospitalização é uma experiência estressante que envolve profunda adaptação da criança às várias mudanças que acontecem no seu dia-a-dia. Contudo, pode ser amenizada pelo fornecimento de certas condições como: presença de familiares, disponibilidade afetiva dos trabalhadores da saúde, informação, atividades recreacionais, entre outras ${ }^{(4,7)}$.

A separação da mãe é o fator que provoca maiores efeitos adversos no processo de hospitalização da criança, principalmente naquelas menores de seis anos de idade ${ }^{(14)}$. Os sentimentos de insegurança, medo, desespero e perda invadem a criança e principalmente sua família, que diante dos acontecimentos, luta com os recursos disponíveis para que o tratamento obtenha sucesso ${ }^{(7,15)}$.

No cotidiano do hospital, são vivenciadas relações sociais permeadas de conflitos, disputas e negociações. Determinadas situações de conflito são reforçadas pelas normas hospitalares e interações estabelecidas no ambiente hospitalar. A sensação de sentir-se dividida entre cuidar da criança hospitalizada e dos demais membros da família é acentuada, quando o hospital não facilita a troca de acompanhantes, ou mesmo, quando a postura da equipe não permite a ausência desse por alguns períodos, de forma que ter um acompanhante deixa de ser um direito da criança e passa a ser apenas um dever de sua família(13).

Os sentimentos de frustração dos pais estão, com freqüência, relacionados à falta de informação sobre procedimentos e tratamentos, desconhecimento das regras e regulamentos hospitalares. Grande parte da frustração pode ser aliviada em uma unidade pediátrica, quando os pais estão cientes do que esperar e do que se espera deles ${ }^{(4-5)}$.

A permanência dos pais tem como significado a garantia de participação nos cuidados básicos da criança e sua operacionalização implicam no desenvolvimento de ações pelos profissionais de saúde como a orientação e o apoio psicológico aos pais quanto aos aspectos específicos do tratamento, medicação e cuidados especiais com a criança e adolescentes, além de orientação quanto à participação nos cuidados básicos aos pacientes $^{(4,15)}$. 
A participação dos pais é uma questão complexa que tem sido tratada de forma fragmentada não reconhecendo a natureza da relação entre pais e enfermeiras como uma parceria integrada(14-15). Favorecer a manutenção do vínculo e do apego mãecriança-família desde o nascimento é um direito da criança e ao se estabelecer o vínculo pressupõe-se o estabelecimento da responsabilidade, não individual, mas do binômio serviço de saúde/profissionais e paciente/família ${ }^{(7,15)}$.

Os pais e a enfermagem têm como meta o cuidado da criança visando 0 atendimento adequado de suas necessidades decorrentes da doença e hospitalização. Nesse sentido, acredita-se que as enfermeiras precisam identificar e compreender as necessidades de informação dos pais para integrá-los no papel que devem assumir durante a hospitalização do filho e entender melhor o que se passa com $e^{(4)}{ }^{(4)}$ É fundamental compreender a família como mediadora da criança/adolescente no hospital, já que, ela é porta-voz das preocupações e sentimentos daqueles que acompanham, transmitindo à equipe os sinais e as mensagens enviadas pela criança/adolescente. Estes sinais podem auxiliar os profissionais a rever sua conduta e promover mudanças na assistência, adequando o mundo do hospital às necessidades da criança ${ }^{(6)}$.

Os estudos apontam ${ }^{(7,15)}$ ainda que os hospitais voltados para a formação dos profissionais da área de saúde, têm mostrado interesse no envolvimento da família quando se trata da internação de crianças. Uma estratégia utilizada é a participação dos pais através da elaboração de projetos, programas de pais participantes e mãe acompanhante ${ }^{(2)}$.

\section{O direito da criança de desfrutar de alguma forma de recreação durante sua permanência no hospital}

$O$ Art. $16^{\circ}$ do ECA trata do direito à liberdade e compreende o brincar, praticar esportes e divertir-se. A Resolução no. $41 \backslash 95$ do CONANDA em seu Art. 9o reforça ainda, o direito de desfrutar de alguma forma de recreação, programas de educação para a saúde, acompanhamento do currículo escolar, durante sua permanência hospitalar ${ }^{(3,8)}$.
Ao considerar a recreação, os programas de educação para a saúde e o acompanhamento do currículo escolar da criança hospitalizada, observamos que dos 13 artigos encontrados, apenas $04(30,8 \%)$ discutem o assunto em seu desenvolvimento.

A atividade recreacional é parte importante do processo terapêutico da criança hospitalizada, mas é também, parte essencial na construção, mais especificamente, na reconstrução de sua identidade ${ }^{(13,16)}$.

Quando a criança é internada, ela é acompanhada pelo medo do tratamento e do desconhecido, pela mudança da sua rotina e pela falta do entendimento do que está acontecendo. Por isso, atualmente é realizado, em algumas instituições, o trabalho que visa levar alegria a essa criança, fazendo assim com que não se restrinja o seu prazer por brincar.

Tratando-se de crianças hospitalizadas, o brinquedo tem também um importante valor terapêutico, influenciando no restabelecimento físico e emocional, pois pode tornar o processo de hospitalização menos traumatizante e mais alegre, fornecendo melhores condições para a recuperação.

A perspectiva da utilização do brinquedo em enfermagem pediátrica é a de servir como meio de comunicação entre os profissionais e a criança e detectar a singularidade de cada uma ${ }^{(17)}$. Do ponto de vista da criança ele promove o desenvolvimento físico, psicológico, social e moral; ajuda-a a perceber o que ocorre consigo, libera temores, raiva, frustração e ansiedade. Ajuda a criança, ainda, a revelar seus pensamentos e sentimentos, promovendo satisfação, diversão e espontaneidade. Assim, brincando ele exercita suas potencialidades ${ }^{(14)}$.

Os estudos apontam a importância de preparar a criança para a realização de procedimentos cirúrgicos e dolorosos através do brincar, desenhar e contar estórias. O brinquedo de dramatização e o brinquedo terapêutico servem para a criança, exteriorizar seus conflitos. Com tais informações a enfermeira pode reforçar ou corrigir as percepções da criança e auxiliá-la a dominar a experiência de se submeter a um procedimento estressante ${ }^{(14)}$. O brincar é a forma infantil da capacidade humana para lidar com as experiências e dominar a realidade ${ }^{(15)}$. 
Além disso, a provisão das facilidades educacionais para a criança é importante em hospitalização de curta ou longa duração, sendo uma responsabilidade do hospital e dos profissionais de saúde e um direito da criança.

\section{Direito a ter seus direitos constitucionais e os contidos no estatuto da criança e adolescente, respeitados pelos hospitais integralmente.}

O cuidar profissional, no qual estão envolvidos os médicos e os enfermeiros, é aquele cuidado que garante a sobrevivência e o alívio dos sintomas e cujos procedimentos, quando executados com delicadeza, sensibilidade e comunicação empática profissional-cliente, possam transmitir confiança e segurança na equipe de saúde.

Os estudos apontam que na visão dos clientes, esse cuidar inclui ações de dar banho no paciente, verificar se tem febre e se está tudo bem, colocar termômetro, fazer anestesia devagarzinho, aliviar sintomas de dor, atender bem e ser delicado, dar força, alcançar a alimentação quando o paciente está só ou quando não consegue alcançá-la e cuidar para o paciente não morrer ${ }^{(16-18)}$.

O cuidar implica em uma relação de confiança na qual o ser cuidado entrega o seu self, que se encontra fragilizado, nas mãos do ser cuidador. Este com sua presença carinhosa e atenciosa possibilita ao paciente reforçar seus mecanismos internos, passando a confiar no ambiente ${ }^{(16)}$.

Em relação à atuação da equipe de enfermagem na unidade pediátrica, pode-se observar que dos artigos analisados, 05 (38,5\%) abordaram a temática, relacionando-a ao cuidado e os direitos da criança hospitalizada, sua família e seu próprio preparo para os procedimentos.

A enfermeira desempenha papel importante, visto ser ela, a profissional que passa a maior parte do tempo em companhia da criança, sendo a responsável pelos cuidados prestados, cabendo-lhe também se empenhar ao máximo para reduzir os riscos de perturbações à criança, decorrentes da hospitalização.

Muitas vezes na ausência da mãe, em enfermarias e berçários, a enfermeira acaba por exercer o papel da mãe substituta. Com a nova perspectiva de trabalhar lado a lado com a mãe nas enfermarias e berçários, ela vê-se no delicado papel de assistir e orientar também a mãe e dividir com ela o cuidado(13).

Estes profissionais que, cotidianamente convivem com a doença, o sofrimento e a morte, desenvolvem maneiras peculiares de enfrentar tal ameaça. São conhecidas e amplamente estudadas as reações mais freqüentes de tais profissionais, sendo que os estudos abordam desde questões da formação até problemas a nível pessoal e institucional decorrentes do contato com a morte ${ }^{(18-19)}$.

Nas questões referentes à comunicação entre a enfermeira e o paciente com doença crônica, mostram que as crianças maiores e os adolescentes provocam maior incômodo e sofrimento porque falam sobre o que vive em decorrência da doença e do tratamento. Os bebês e as crianças menores, por não se expressarem verbalmente com a mesma clareza, são considerados mais fáceis de serem cuidados, por não demandarem esforço emocional na mesma intensidade que os pacientes que se expressam através da fala. Assim, a expressão verbal é tomada como referência, capaz de modular afetivamente as relações estabelecidas e direcionar a atuação da enfermeira(19-20).

A prática assistencial da enfermagem implica no cumprimento de atividades que atendam os direitos da criança e adolescente hospitalizado e de um padrão de qualidade do cuidar.

\section{CONCLUSÃO}

Após treze anos de existência dos Direitos da Criança e do Adolescente Hospitalizados instituídos desde 1995 pela Resolução no. 41\95 do CONANDA, os estudos revelam que à criança no contexto hospitalar, em sua maioria, não referenciam tal Resolução. Essa Resolução é de suma importância, pois integra os pais à internação de seu filho, tornando-os mais participativos. Além disso, minimiza o estresse da criança frente à internação.

Levando em consideração que a enfermagem vê o seu cliente como um todo, dando atenção a todas as necessidades básicas deste, podemos dizer que os profissionais de enfermagem pediátrica devem assegurar os 
direitos das crianças e de seus familiares, visando assim à otimização da assistência. Para isso, os pais, a família e a criança hospitalizada necessitam: de informações sobre os seus direitos, da presença sem restrições dos pais ou responsáveis, informações sobre a doença e as razões da hospitalização, higienização para promover o bem estar e evitar infecções hospitalares, de um ambiente criativo e sem muitos ruídos para amenizar a tensão, de recreação para continuar exercendo suas habilidades, de visitas para manter a segurança e confiança, e de um acompanhamento psicológico objetivando diminuir o sofrimento inerente ao adoecimento e a hospitalização.

Contudo, é notório o quão importante é esta temática e ao mesmo tempo, o fato de não haver muitas publicações em torno dela. Foi verificado através deste estudo, que a maioria dos artigos encontrados, foram realizados por enfermeiros, porém sabemos que ainda é necessária uma maior sensibilização por parte dos profissionais, não só da enfermagem como de toda área da saúde, pesquisar e atuar de forma eficaz na assistência das crianças hospitalizadas, que se encontram em um momento muito frágil de suas vidas.

\section{REFERÊNCI AS}

1. Hockenberry MJ, Wilson D, Winkelstein ML. Wong. Fundamentos de enfermagem. 7ạ edição. Rio de J aneiro: Elsevier; 2006.

2. Collet N, Rocha SMM. Criança hospitalizada: mãe e enfermagem compartilhando o cuidado. Rev. Latino-Am. Enfermagem [I nternet]. 2004 [cited 2008 jun 16];12(2):191-7. Available from: http://www.scielo.br/pdf/rlae/v12n2/v12n2a0 7.pdf.

3. Ministério da Saúde. Estatuto da criança e do adolescente. Brasília (Brasil): Ministério da Saúde; 1991.

4. Sabatés AL, Borba RIH. As informações recebidas pelos pais durante a hospitalização do filho. Rev. Latino-Am. Enfermagem [Internet]. 2005 [cited 2008 jun 16];13(6):968-73. Available

from: http://www.scielo.br/pdf/rlae/v13n6/v13n6a0 8.pdf.

5. Lima RAG, Rocha SMM, Scochi CGS. Assistência à criança hospitalizada: reflexões acerca da participação dos pais. Rev. Latino-Am.
Enfermagem [Internet]. 1999 [cited 2008 jun 16]; 7(2):33-9.

Available

from: http://www. scielo.br/pdf/rlae/v7n2/1345 9.pdf.

6. Fernandes CNS, Andraus LMS, Munari DB. O aprendizado do cuidar da família da criança hospitalizada por meio de atividades grupais. Rev. Eletr. de Enf. [Internet]. 2006 [cited 2008 jun 16];08(01):108-18. Available from: http://www. fen.ufg. br/revista/revista8_1/ original_14.htm.

7. Collet N, Oliveira BRG. Criança hospitalizada: percepção das mães sobre o vínculo afetivo criança-família. Rev. Latino-Am. Enfermagem [Internet]. 1999 [cited 2008 jun 16];7(5):95102.

Available

from: http://www.scielo.br/pdf/rlae/v7n5/1350 9.pdf.

8. Conselho Nacional de Defesa dos Direitos da Criança e Adolescente (Brasil). Resolução no 41, 13 de outubro de 1995. Dispõe sobre os direitos da criança hospitalizada. Diário Oficial da República Federativa do Brasil (BR): Seção I, p.16319-20, 17 de outubro de 1995.

9. Instituto de Apoio à Criança. Carta da criança hospitalizada. Humanização dos serviços de atendimento à criança. IAC (Lisboa); 1998.

10. Conselho Federal de Enfermagem. Código de ética dos profissionais de enfermagem. Brasília (Brasil): COFEN; 1993.

11. Lobiondo-Wood, Geri HJ. Pesquisa em enfermagem: métodos, avaliação crítica e utilização. 4a edição. Rio de Janeiro: Guanabara Koogan; 2001.

12. Minayo MCS. O desafio do conhecimento: pesquisa qualitativa em saúde. Rio de Janeiro: Hucitec-Abrasco; 1999.

13. Francarini GM, Zilioli D, Silva PRF, Sant'ana RPM, Lima RAG. Prescrição do dia: infusão de alegria. Utilizando a arte como instrumento na assistência à criança hospitalizada. Rev. LatinoAm. Enfermagem [Internet]. 1998 [cited 2008 jun 16];6(5):27-33. Available from: http://www.scielo.br/pdf/rlae/v6n5/1385 7.pdf.

14. Pinto JP, Ribeiro CA, Silva CV. Procurando manter o equilíbrio para atender suas demandas e cuidar da criança hospitalizada: a experiência da família. Rev. Latino-Am. Enfermagem [Internet]. 2005 [cited 2008 jun 16]; 13(6): 97481.

Available 
from: http://www.scielo.br/pdf/rlae/v13n6/v13 n6a09.pdf.

15. Ferreira EA, Vargas IMÁ, Rocha SMM. Um estudo bibliográfico sobre o apego mãe e filho: bases para a assistência de enfermagem pediátrica e neonatal. Rev. Latino-Am. Enfermagem [Internet]. 1998 [cited 2008 jun 16];6(4):111-16. Available from: http://www. scielo.br/pdf/rlae/v6n4/1388 2.pdf.

16. Gonzaga MLC, Arruda EN. Fontes e significados de cuidar e não cuidar em hospital pediátrico. Rev. Latino-Am. Enfermagem [Internet]. 1998 [cited 2008 jun 16];6(5):17-26. Available

from: http://www. scielo.br/pdf/rlae/v6n5/1385 6.pdf.

17. Furtado MCC, Lima RAG. Brincar no hospital: subsídios para o cuidado de enfermagem. Rev. esc. enferm. USP [Internet]. 1999 [cited 2008 jun 16];33(4):364-69. Available from: http://www.ee.usp.br/reeusp/upload/pdf/471. pdf

18. Francoso, LPC. Reflexões sobre o preparo do enfermeiro na área de oncologia pediátrica. Rev. Latino-Am. Enfermagem [Internet]. 1996 [cited 2008 jun 16];4(3):41-8. Available from: http://www.scielo.br/pdf/rlae/v4n3/v4n3a04. pdf.

19. Neirahuerta EP. Preparo da criança e família para procedimentos cirúrgicos: intervenção de enfermagem. Rev. esc. enferm. USP [Internet]. 1996 [cited 2008 jun 16];30(2):340-53. Available

from: http://www.ee.usp.br/reeusp/upload/pdf/352. pdf.

20. Valle ERM, Melo LL. Equipe de enfermagem, criança com câncer e sua família: uma relação possível. Revista Virtual - Pediatria Moderna [internet]. 1999 [cited 2008 jun 16];35:97073. Available

from: http://www.uftm.edu.br/dispsicologiaapls au/atua/AVI dispsicologiaaplsau070420152609.p df.

Artigo recebido em 14.08.07

Aprovado para publicação em 30.09.08 